\title{
The prevalence and prognostic impact of tumor-infiltrating lymphocytes in uterine carcinosarcoma
}

\author{
Jesse Lopes da Silva ${ }^{1,2^{*}}$, Lucas Zanetti de Albuquerque ${ }^{1}$, Fabiana Resende Rodrigues ${ }^{3}$, \\ Guilherme Gomes de Mesquita ${ }^{1,3}$, Cláudia Bessa Pereira Chaves ${ }^{1,2}$, Martín Hernán Bonamino ${ }^{4,5}$ and \\ Andreia Cristina de Melo ${ }^{1}$
}

\begin{abstract}
Objective: To examine the prevalence and prognostic role of tumor microenvironment (TME) markers in uterine carcinosarcoma (UCS) through immunohistochemical characterization.

Methods: The internal database of our institution was queried out for women with UCS who underwent surgery and thereafter postoperative chemotherapy with carboplatin and paclitaxel between January 2012 and December 2017. Tissue microarrays containing surgical samples of UCS from 57 women were assessed by immunohistochemistry for CD3, CD4, CD8, FOXP3, PD-1, PD-L1, and PD-L2.

Results: The mean age was 65.3 years (range, 49 to 79 years). For the epithelial component (E), CD3_E and CD4_E were highly expressed in 38 (66.7\%) and in 40 (70.1\%) patients, respectively, and were significantly associated with more advanced stages ( $p=0.038$ and $p=0.025$, respectively). CD8_E was highly expressed in 42 (73.7\%) patients, FOXP3_E 16 (28.1\%), PD-1_E 35 (61.4\%), PD-L1_E 27 (47.4\%) and PD-L2_E 39 (68.4\%). For the sarcomatous component (S), the prevalence of high expression was: CD3_S 6 (10.5\%), CD4_S 20 (35.1\%), CD8_S 44 (77.2\%), FOXP3_S 8 (14\%), PD-1_S 14 (24.6\%), PD-L1_S 14 (24.6\%) and PD-L2_S 8 (14\%). By multivariate analysis, the CD8/FOXP3_S ratio $(p=0.026), C D 4 \_E(p=0.010), P D-L 1 \_E(p=0.013)$ and PD-L1_S $(p=0.008)$ markers significantly influenced progression-free survival. CD4/FOXP3_S ratio $(p=0.043)$, PD-1_E $(p=0.011)$, PD-L1_E $(p=0.036)$ and PD-L1_S $(p=0.028)$ had a significant association with overall survival.
\end{abstract}

Conclusion: Some differences in UCS clinical outcomes may be due to the subtype of TILs and PD-1/PD-L1 axis immune checkpoint signaling.

Keywords: Uterine carcinosarcoma, Tumor-infiltrating lymphocyte, Tumor microenvironment, Immune biomarkers, Tumor microenvironment

${ }^{*}$ Correspondence: jesse.silva@inca.gov.br

${ }^{2}$ Gynecologic Oncology Section, Brazilian National Cancer Institute, Rio de Janeiro, Brazil

Full list of author information is available at the end of the article

\section{Introduction}

Uterine carcinosarcomas (UCS) are uncommon and overly aggressive tumors with biphasic histology composed of epithelial (E) and sarcomatous (S) elements $[1,2]$. Recently, these tumors have been thought to be derived from monoclonal carcinoma cells branched from embryonal mesoderm [3]. Given that, UCS are pointed out as a model for epithelial-mesenchymal transition, 
a mechanism that results in loss of cell polarity, adhesion, migratory and invasive properties, which facilitates metastasis [4].

UCS account for less than $5 \%$ of uterine cancers and the incidence ranges from 5.1 to 6.9 per $1,000,000$ person-years worldwide [5]. This tumor is usually diagnosed in older women, with a median age ranging from 62 to 67 years [6]. African-American women are significantly at more risk of having UCS compared to Caucasian women [7]. In contrast, there is no Brazilian data regarding UCS specifically.

The tumor microenvironment (TME) plays an important role in the progression and metastasis of tumors through the so-called "cancer immunoediting" mechanism that leads to escape of cancer cells from immune surveillance [8]. Several cell types of the innate and adaptive immune system are involved in this complex process, including CD8+ lymphocytes, Th1/Th2 subclasses of CD4+ T lymphocytes, natural killer (NK) cells and forkhead box protein 3 (FOXP3+) $\mathrm{T}$ regulatory (Treg) cells [9]. Recently, much has been discussed about the subtyping of tumor-infiltrating lymphocytes (TILs) in neoplasms of different sites [10].

The programmed death 1 receptor (PD-1), found on the surface of activated $\mathrm{T}$ cells and many other immune cells, is currently one of the most studied immune regulatory pathways able to strongly influence the mechanism of carcinogenesis, with a great potential of prognostic and therapeutic effect [11]. PD-1 with its ligands, programmed death-ligand 1 (PD-L1) and programmed death-ligand 2 (PD-L2), play a crucial role in tumor immune evasion. The immune checkpoint pathways inhibit $\mathrm{T}$ cell receptor (TCR) signaling via engagement of SHP-1 and SHP-2 phosphatases, resulting in reduced T-cell proliferation and cytokine production, increasing susceptibility to apoptosis [12]. The Inhibition of the PD-1/PD-L1/PD-L2 interaction by different immunological therapies can cause the $\mathrm{T}$ cell function to be restored, providing enhanced anti-tumor immune responses [13].

So far, no effective immune biomarkers have been timely assessed for UCS. This cohort aimed to gain a better insight into the prevalence and prognostic value of TILs subtype, and also PD-1, PD-L1 and PD-L2 expression in patients with UCS.

\section{Materials and methods}

\section{Patient selection and data collection}

This study was approved by the Ethics in Human Research Committee of the Brazilian National Cancer Institute (INCA), Rio de Janeiro, Brazil, and was conducted following the Good Clinical Practice Guidelines. All women diagnosed with UCS, who underwent surgery and thereafter postoperative chemotherapy with the standard dose of every-3-week carboplatin AUC 5 and paclitaxel $175 \mathrm{mg} / \mathrm{m}^{2}(\mathrm{CP})$ for six cycles [14] at INCA between January 2012 and December 2017, were identified through the internal database. Patients with a scarce or inadequate pathological sample, with synchronous or anachronistic tumors, were excluded from this cohort. Clinical data regarding sociodemographic factors, staging, surgery, histological subtype (homologous versus heterologous), progression and survival were retrospectively obtained in the medical records. The staging was performed based on the criteria of the International Federation of Gynecology and Obstetrics (FIGO, 2009) [15].

\section{Immunohistochemistry}

The tissue microarray (TMA) was built using samples of stromal areas of greatest tumor cellularity present in formalin-fixed paraffin-embedded primary tumors in surgical specimens. Three cores were punched in each of the two tumor components (E and S). All immunohistochemistry (IHC) analyses were performed on 4- $\mu \mathrm{m}$ sections following standard procedures. TMA samples were immunostained for CD3 (clone MRQ-39, Cell Marque, diluted 1:1000), CD4 (clone SP35, Cell Marque, diluted 1:400), CD8 (clone SP 16, Cell Marque, diluted 1:1000), FOXP3 (clone 236A/E7, Abcam, diluted 1:50), PD-1 (clone NAT105, Cell Marque, diluted 1:100), PD-L1 (clone SP142, Ventana, prediluted) and PD-L2 (clone ab200377, Abcam, diluted 1:200). The tumor cell staining was compared with that of negative controls made from counterstaining with hematoxylin and positive controls.

Intratumoral stromal immune markers were manually counted and scored as described hereafter. For PD-L1, PD-L2 and PD-1, the slides were scored according to the percentage of positive immune and tumor cells divided by the number of fields to calculate the mean value for each case, determined at 40x magnification [16]. For TILs subpopulations (CD3+, CD4+, CD8+ and FOXP3+) intratumoral stromal lymphocytes were counted manually and quantified as the average absolute number of immunolabeled lymphocytes at each observed field at 40x magnification [17].

For statistical purposes, the scores of these biomarkers were dichotomized into low and high-level groups for each of the histological elements, E and S, based on cutoff points calculated according to the surv_cutpoint function of the survminer R package [18]. Thus, the cut-off for CD 3_E was 0, CD3_S was 60, CD4_E was 0, CD4_S was 20, CD8_E was 0, CD8_S was 1, FOXP3_E was 0 , FOXP3_S was 5, PD-1_E was 0, PD-1_S was 1, PD-L1_E was 1 , PD-L1_S was 20, PD-L2_E was 40 and PD-L2_S was 90. Likewise, the cutoff for ratios: CD4/FOXP3_E+ was 1, CD4/FOXP3_S+ was 2, CD8/FOXP3_E+ was 3, CD8/FOXP3_S+ was 3.7, CD8/CD4_E+ was 0.18 and 
CD8/CD4_S+ was 3. The boxplots shown in additional Fig. 1 represent the distributions of the values of markers evaluated. The pathological analysis was performed twice for each slide of TMA by two experienced pathologists.

\section{Statistical analysis}

Progression-free survival (PFS) was calculated from the date of first CP infusion to the earliest date of disease progression, recurrence, or death. Overall survival (OS) was calculated from the first $\mathrm{CP}$ infusion to the date of death of any cause or censored if the patient was known to be alive on the last day of data collection. The KaplanMeier method was used to estimate PFS and OS for each variable. Patients were stratified by age, body mass index (BMI), race, stage, omentectomy, residual disease, adjuvant radiotherapy, lymphovascular invasion (LVI), histological subtype and IHC markers status. All continuous variables were evaluated by the Shapiro-Wilk test of normality. Categorical variables were described by their absolute and relative frequencies.

To assess the association of the IHC markers scores with mean age and BMI, the Student's t-test was used. The correlation with categorical clinicopathological parameters was performed by Pearson's chi-squared test and, when applicable, by Fisher's exact test. A further analysis comparing the paired scores of immunohistochemistry factors for epithelial and sarcomatous components was performed by the Wilcoxon signed-rank test. The crude Hazard Ratio (HR) for each variable was calculated by the Cox proportional hazards. The variables evaluated for survival outcomes on univariate analysis were adjusted for the FIGO stage in multivariate models. A $p$-value $<0.05$ was considered statistically significant. The missing data were excluded from the analysis. The statistical analyses were conducted using the $\mathrm{R}$ project version 3.5.3 [18].

\section{Results}

The clinicopathological and IHC data of the 57 women included in this cohort were summarized in Tables 1 and 2. The mean age was 65.3 years (range, 49 to 79 years). Briefly, there was a predominance of women $\geq 60$ years old (40 cases, $70.2 \%$ ), non-Caucasians (42 cases, $75 \%$ ), with advanced disease (42 cases, 73.7\%), heterologous subtype (30 cases, $71.4 \%$ ), and LVI was detected in 25 cases (60.1\%) (additional Table 1). As for treatment data, 37 (65\%) patients were submitted to lymphadenectomy, 27 (47.4\%) patients underwent omentectomy, optimal debulking (defined as residual disease $<1.0 \mathrm{~cm}$ ) was achieved in $39(68.4 \%)$ and adjuvant radiotherapy was provided to 24 (42.8\%) patients (additional Table 2).

By analyzing the E component, CD3_E was highly expressed in 38 (66.7\%) patients and significantly associated with more advanced stages $(p=0.038)$. CD4_E was highly expressed in $40(70.1 \%)$ patients and was significantly associated with more advanced stages $(p=0.025)$. CD8_E, FOXP3_E and PD-1_E were at a high level in 42 (73.7\%), 16 (28.1\%) and 25 (43.9\%) patients, respectively, but did not show significant association with any of the clinicopathological features. PD-L1_E was overexpressed in $27(47.4 \%)$ patients and was significantly more highly expressed in patients $\geq 60$ years old $(p=0.022)$ (Table 1). As for the assessment of IHC markers in the $S$ component, the frequencies of highly positive expression were much lower in CD3_S (6 cases, 10.5\%) and CD4_S (20 cases, 35.1\%). CD8_S was expressed in 44 cases $(77.2 \%)$, FOXP3_S in 8 cases (14\%), PD-1_S in 14 cases $(24.6 \%)$, PD-L1_S in 14 cases $(24.6 \%)$ and PDL2_S in 8 cases (14\%) (Table 2). Except for PD-L1, all other TME markers (CD3, CD4, CD8, FOXP3, PD-1 and PD-L2) showed significantly greater expression in the sarcomatous component than in the epithelial component (additional Table 5). Additional Fig. 2 shows representative images of cases with high expression of IHC markers.

With a median follow-up of 51 months (95\% confidence interval, CI: 40-70), 42 patients had disease progression or died until the moment of the analysis, and the threeyear rate of progression-free survival in the general study population was $21.2 \%$ (95\% CI: $11.7-38.1$ ). The outcome PFS was compared according to the clinicopathological parameters and IHC evaluations. As stated by the data in Table 3 , patients with early stages I/II had $63 \%$ lower risk of progression than advanced stages III/IV (Hazard ratio, HR 0.37; 95\% CI: $0.16-0.84 ; p=0.017$ ). By multivariate analysis for PFS, patients with high expression of CD4_E (high vs low; HR 0.43; 95\% CI: $0.23-0.82 ; p=0.010$ ), PD-L1_E (high versus low; HR 0.45; 95\% CI: 0.24-0.84; $p=0.013$ ) and PD-L1_S (high versus low; HR 0.30; $95 \%$ CI: $0.12-0.74 ; p=0.008$ ) had significantly lower risk of progression or death. Conversely, patients with residual disease after surgery (R1/2 versus R0; HR 3.09; 95\% CI: $1.34-7.08 ; p=0.008$ ) and high CD8/FOXP3_S ratio (high versus low; HR 2.05 ; 95\% CI: $1.08-3.85 ; p=0.026)$ significantly yielded poorer OS.

By the moment of the analysis, 38 patients died, and the three-year OS rate was $29.4 \%$ (95\% CI: 18.1-47.6). As shown in Table 4, patients with early-stage disease I/II had a risk of death $72 \%$ lower than advanced stages III/IV (HR 0.28; 95\% CI: 0.11-0.71; $p=0.008$ ). Regarding multivariate analysis for OS, patients with high expression of PD1_E (high vs low; HR 0.39; 95\% CI: 0.19-0.81; $p=0.011$ ), PD-L1_E (high versus low; HR 0.49; 95\% CI: $0.25-0.96 ; p=0.037$ ) and PD-L1_S (high versus low; HR 0.37; 95\% CI: $0.15-0.90 ; p=0.028$ ) had significantly lower risk of death. By contrast, there was significantly worse 


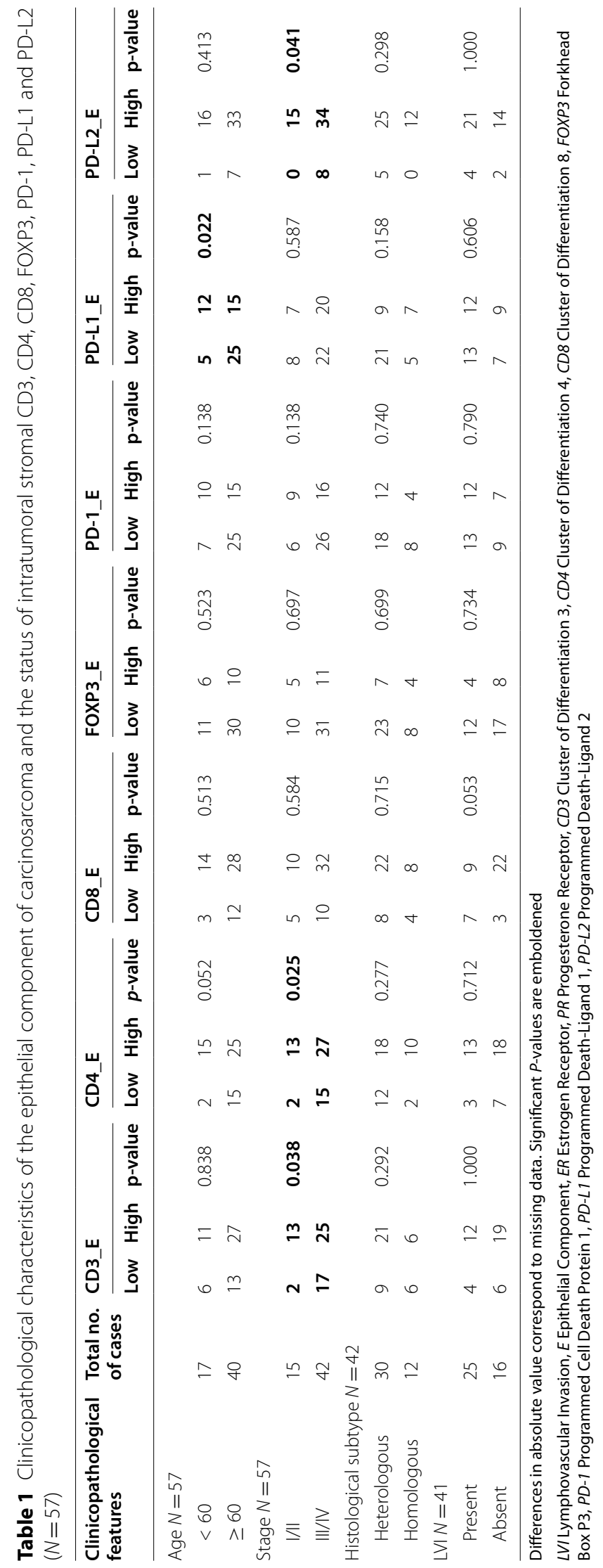




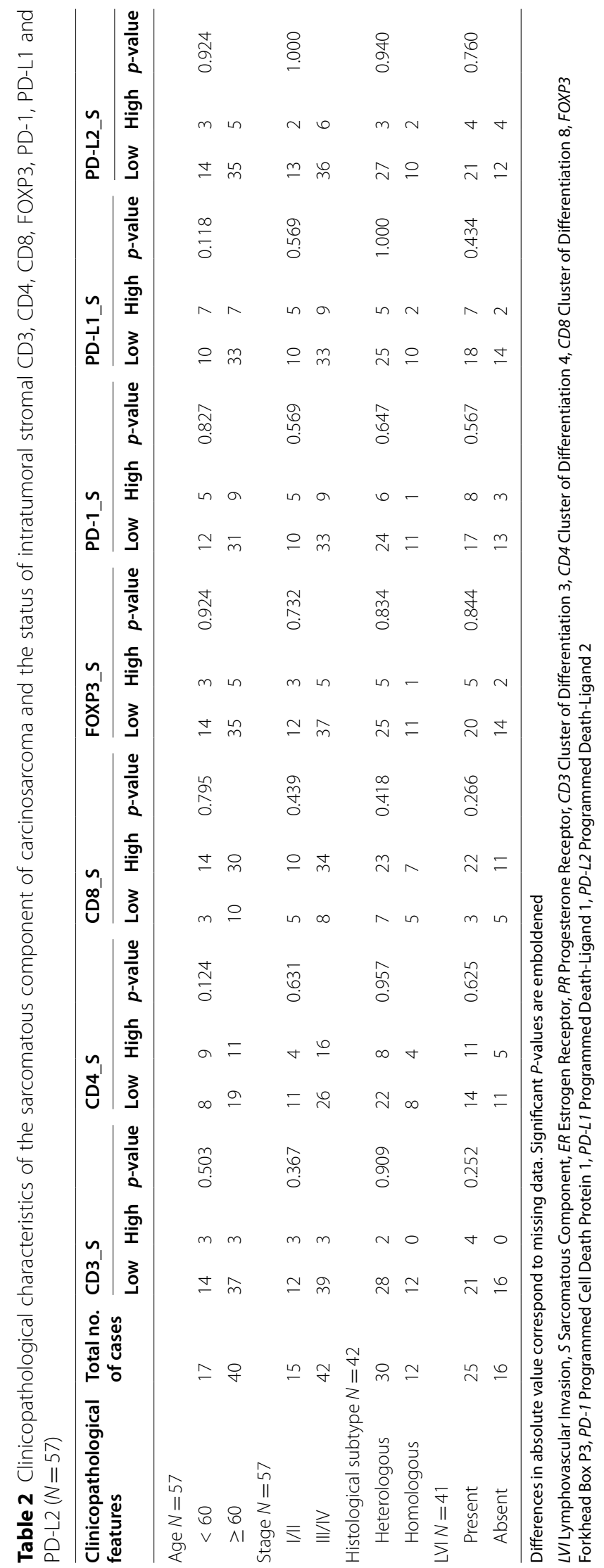


Table 3 Crude and adjusted Hazards Ratios for Carcinosarcoma progression-free survival (PFS) estimated by univariate analysis and multivariate analysis

\begin{tabular}{|c|c|c|c|c|c|c|}
\hline \multirow[t]{2}{*}{ Clinicopathological features } & \multicolumn{3}{|c|}{ Univariate analysis } & \multicolumn{3}{|c|}{ Multivariate analysis } \\
\hline & HR & $95 \% \mathrm{Cl}$ & $p$-value & HR & $95 \% \mathrm{Cl}$ & $p$-value \\
\hline Age $(<60$ vs. $\geq 60)$ & 1.03 & $0.99-1.07$ & 0.171 & 1.03 & $0.99-1.07$ & 0.111 \\
\hline Stage (I/II vs III/IV) & 0.37 & $0.16-0.84$ & 0.017 & - & - & - \\
\hline Residual disease (R1/2 vs R0) & 4.19 & $2.13-8.25$ & 0.001 & 3.09 & $1.34-7.08$ & 0.008 \\
\hline Adjuvant radiotherapy (Yes vs No) & 0.57 & $0.30-1.08$ & 0.087 & 0.66 & $0.34-1.26$ & 0.213 \\
\hline LVI (present vs absent) & 1.06 & $0.50-2.25$ & 0.872 & 1.05 & $0.49-2.22$ & 0.906 \\
\hline $\begin{array}{l}\text { Histological subtype (Homologous vs } \\
\text { Heterologous) }\end{array}$ & 0.83 & $0.39-1.78$ & 0.631 & 0.94 & $0.44-2.02$ & 0.885 \\
\hline CD3_E (high vs low) & 0.58 & $0.31-1.08$ & 0.086 & 0.67 & $0.26-1.27$ & 0.229 \\
\hline CD3_S (high vs low) & 0.48 & $0.15-1.57$ & 0.225 & 0.62 & $0.19-2.07$ & 0.439 \\
\hline CD4_E (high vs low) & 0.39 & $0.21-0.74$ & 0.004 & 0.43 & $0.23-0.82$ & 0.010 \\
\hline CD4_S (high vs low) & 0.62 & $0.80-3.21$ & 0.184 & 0.60 & $0.30-1.20$ & 0.153 \\
\hline CD8_E (high vs low) & 0.67 & $0.35-1.29$ & 0.232 & 0.61 & $0.31-1.19$ & 0.151 \\
\hline CD8_S (high vs low) & 0.86 & $0.42-1.75$ & 0.669 & 0.71 & $0.34-1.48$ & 0.364 \\
\hline FOXP3_E (high vs low) & 0.55 & $0.26-1.17$ & 0.120 & 0.54 & $0.26-1.16$ & 0.115 \\
\hline FOXP3_S (high vs low) & 0.41 & $0.14-1.15$ & 0.090 & 0.42 & $0.15-1.19$ & 0.103 \\
\hline PD-1_E (high vs low) & 0.47 & $0.25-0.90$ & 0.022 & 0.54 & $0.28-1.04$ & 0.065 \\
\hline PD-1_S (high vs low) & 0.66 & $0.31-1.41$ & 0.286 & 0.73 & $0.34-1.56$ & 0.420 \\
\hline PD-L1_E (high vs low) & 0.47 & $0.25-0.88$ & 0.019 & 0.45 & $0.24-0.84$ & 0.013 \\
\hline PD-L1_S (high vs low) & 0.28 & $0.12-0.67$ & 0.004 & 0.30 & $0.12-0.74$ & 0.008 \\
\hline PD-L2_E (high vs low) & 0.48 & $0.22-1.06$ & 0.070 & 0.62 & $0.28-1.38$ & 0.241 \\
\hline PD-L2_S (high vs low) & 0.46 & $0.16-1.31$ & 0.147 & 0.43 & $0.15-1.22$ & 0.114 \\
\hline CD4/FOXP3_E ratio (high vs low) & 0.57 & $0.31-1.04$ & 0.067 & 0.63 & $0.34-1.16$ & 0.141 \\
\hline CD4/FOXP3_S ratio (high vs low) & 1.43 & $0.76-2.67$ & 0.267 & 1.65 & $0.87-3.11$ & 0.120 \\
\hline CD8/FOXP3_E ratio (high vs low) & 0.74 & $0.39-1.41$ & 0.363 & 0.84 & $0.44-1.60$ & 0.605 \\
\hline CD8/FOXP3_S ratio (high vs low) & 2.27 & $1.21-4.26$ & 0.010 & 2.05 & $1.08-3.85$ & 0.026 \\
\hline CD8/CD4_E ratio (high vs low) & 0.61 & $0.24-1.56$ & 0.299 & 0.51 & $0.20-1.33$ & 0.171 \\
\hline CD8/CD4_S ratio (high vs low) & 1.69 & $0.78-3.67$ & 0.186 & 1.87 & $0.86-4.10$ & 0.113 \\
\hline
\end{tabular}

All variables were adjusted for staging in multivariate analysis. Significant $P$-values are emboldened

LVI Lymphovascular Invasion, E Epithelial Component, S Sarcomatous Component, ER Estrogen Receptor, PR Progesterone Receptor, CD3 Cluster of Differentiation 3, CD4 Cluster of Differentiation 4, CD8 Cluster of Differentiation 8, FOXP3 Forkhead Box P3, PD-1 Programmed Cell Death Protein 1, PD-L1 Programmed Death-Ligand 1, PD-L2 Programmed Death-Ligand 2

prognosis for patients with incomplete debulking (R1/2 versus R0; HR 2.87; 95\% CI: $1.40-5.89 ; p=0.003$ ) and low CD4/FOXP3_S ratio (high versus low; HR 2.04; 95\% CI: $1.02-4.09 ; p=0.043$ ).

Figures 1 and 2 show the Kaplan-Meier curves for PFS and OS according to the evaluated variables, respectively. Other complementary clinicopathological parameters did not influence the outcomes of PFS or OS (additional Tables 4 and 5).

\section{Discussion}

Some of the main clinicopathological features of UCS in the current study are in line with previous reports of large cohorts performed by Matsuo et al. through multicenter studies and examining The Surveillance, Epidemiology, and End Results (SEER) program database [19-22]. In this regard, the mean age greater than 60 years and the LVI present in most patients are highlighted. Conversely, advanced-stage disease at diagnosis and heterologous sarcomatous component were more frequent characteristics in this cohort, perhaps due to the delay in diagnosis and local characteristics, respectively.

There is a growing body of evidence supporting the role of TME in the development and growth of solid tumors. Through pro-inflammatory cytokines actively secreted by tumor cells, leukocytes of the innate and adaptive immune system, including macrophages, neutrophils, NK cells, dendritic cells, mast cells, $\mathrm{T}$ and $\mathrm{B}$ lymphocytes, that infiltrate into the TME [23-26]. Thus, a better understanding of the composition of the 
Table 4 Crude and adjusted Hazards Ratios for Carcinosarcoma Overall survival (OS) estimated by univariate analysis and multivariate analysis

\begin{tabular}{|c|c|c|c|c|c|c|}
\hline \multirow[t]{2}{*}{ Clinicopathological features } & \multicolumn{3}{|c|}{ Univariate analysis } & \multirow{2}{*}{$\begin{array}{l}\text { Multivariate } \\
\text { analysis } \\
\text { HR }\end{array}$} & \multirow[b]{2}{*}{$95 \% \mathrm{Cl}$} & \multirow[b]{2}{*}{$p$-value } \\
\hline & HR & $95 \% \mathrm{Cl}$ & $p$-value & & & \\
\hline Age & 1.02 & $0.98-1.07$ & 0.307 & 1.03 & $0.98-1.08$ & 0.157 \\
\hline Stage (I/II vs III/IV) & 0.28 & $0.11-0.71$ & 0.008 & - & & \\
\hline Residual disease (R1/2 vs R0) & 3.83 & $1.92-7.62$ & 0.001 & 2.87 & $1.40-5.89$ & 0.003 \\
\hline Adjuvant radiotherapy (Yes vs No) & 0.53 & $0.27-1.05$ & 0.068 & 0.64 & $0.32-1.28$ & 0.214 \\
\hline LVI (present vs absent) & 1.05 & $0.47-2.35$ & 0.900 & 0.99 & $0.44-2.22$ & 0.985 \\
\hline $\begin{array}{l}\text { Histological subtype (Homologous vs } \\
\text { Heterologous) }\end{array}$ & 0.84 & $0.38-1.87$ & 0.671 & 0.90 & $0.40-2.01$ & 0.806 \\
\hline CD3_E (high vs low) & 0.52 & $0.27-0.99$ & 0.047 & 0.65 & $0.33-1.25$ & 0.200 \\
\hline CD3_S (high vs low) & 0.54 & $0.16-1.79$ & 0.315 & 0.73 & $0.22-2.42$ & 0.605 \\
\hline CD4_E (high vs low) & 0.52 & $0.26-1.01$ & 0.054 & 0.56 & $0.28-1.11$ & 0.972 \\
\hline CD4_S (high vs low) & 0.66 & $0.32-1.33$ & 0.241 & 0.60 & $0.30-1.22$ & 0.160 \\
\hline CD8_E (high vs low) & 0.69 & $0.35-1.39$ & 0.301 & 0.60 & $0.29-1.23$ & 0.163 \\
\hline CD8_S (high vs low) & 0.77 & $0.37-1.59$ & 0.478 & 0.61 & $0.29-1.28$ & 0.193 \\
\hline FOXP3_E (high vs low) & 0.46 & $0.20-1.06$ & 0.069 & 0.43 & $0.18-1.01$ & 0.052 \\
\hline FOXP3_S (high vs low) & 0.24 & $0.06-0.99$ & 0.048 & 0.26 & $0.06-1.09$ & 0.066 \\
\hline PD-1_E (high vs low) & 0.33 & $0.16-0.68$ & 0.002 & 0.39 & $0.19-0.81$ & 0.011 \\
\hline PD-1_S (high vs low) & 0.46 & $0.19-1.10$ & 0.080 & 0.52 & $0.22-1.27$ & 0.152 \\
\hline PD-L1_E (high vs low) & 0.54 & $0.28-1.03$ & 0.062 & 0.49 & $0.25-0.96$ & 0.037 \\
\hline PD-L1_S (high vs low) & 0.34 & $0.14-0.81$ & 0.015 & 0.37 & $0.15-0.90$ & 0.028 \\
\hline PD-L2_E (high vs low) & 0.56 & $0.24-1.29$ & 0.173 & 0.76 & $0.32-1.77$ & 0.519 \\
\hline PD-L2_S (high vs low) & 0.44 & $0.13-1.44$ & 0.174 & 0.41 & $0.12-1.35$ & 0.144 \\
\hline CD4/FOXP3_E ratio (high vs low) & 0.67 & $0.36-1.27$ & 0.223 & 0.76 & $0.40-1.45$ & 0.407 \\
\hline CD4/FOXP3_S ratio (high vs low) & 1.83 & $0.92-3.65$ & 0.086 & 2.04 & $1.02-4.09$ & 0.043 \\
\hline CD8/FOXP3_E ratio (high vs low) & 0.68 & $0.35-1.33$ & 0.262 & 0.79 & $0.40-1.57$ & 0.506 \\
\hline CD8/FOXP3_S ratio (high vs low) & 2.22 & $1.14-4.29$ & 0.018 & 1.91 & $0.98-3.73$ & 0.058 \\
\hline CD8/CD4_E ratio (high vs low) & 0.69 & $0.27-1.78$ & 0.446 & 0.58 & $0.23-1.51$ & 0.268 \\
\hline CD8/CD4_S ratio (high vs low) & 0.98 & $0.39-2.53$ & 0.969 & 1.16 & $0.45-3.01$ & 0.754 \\
\hline
\end{tabular}

All variables were adjusted for staging in multivariate analysis. Significant $P$-values are emboldened

LVI Lymphovascular Invasion, E Epithelial Component, S Sarcomatous Component, ER Estrogen Receptor, PR Progesterone Receptor, CD3 Cluster of Differentiation 3, CD4 Cluster of Differentiation 4, CD8 Cluster of Differentiation 8, FOXP3 Forkhead Box P3, PD-1 Programmed Cell Death Protein 1, PD-L1 Programmed Death-Ligand 1, PD-L2 Programmed Death-Ligand 2

lymphomononuclear infiltrate in TME has paved the way as biomarkers for a more personalized anticancer therapy. Many immunotherapeutic agents, including immunomodulators, vaccines, adoptive transfer of endogenous or genetically modified $\mathrm{T}$ cells, cytokines, and mainly immune checkpoint inhibitors (ICIs), have shown remarkably beneficial effects for better therapeutic response and increased survival in gynecologic cancers [27].

To the best of our knowledge, there is no previous published data assessing the predictive or prognostic role of TME markers in UCS so far. Likewise, studies on the characterization of TME in gynecological cancer are very scarce. Zhang et al. [28] investigated the prognostic impact of TME profile in 221 patients with endometrial cancer. Similar to our results, highly expressed CD4+ TILs were significantly associated with better OS and longer treatment-free interval and may be associated with chemosensitivity. Jong et al. [29] have recently reported 368 FIGO stage I-IV endometrial cancer patients with highly expressed CD8+ TILs, a marker for killer cytotoxic T cells, and a high CD8 +/ FOXP3+ ratio was associated with better disease-free survival. FOXP3 is the most specific marker for Treg cells and, often associated with a negative impact on survival in several types of cancer, is likely to have an important role in suppressing anti-tumor immunity [30, 31]. Ore-Arce et al. [32] also reported that high CD8+ TILs was significantly associated with better 5 -year OS in 68 women with FIGO stage I-IV endometrial cancer. 

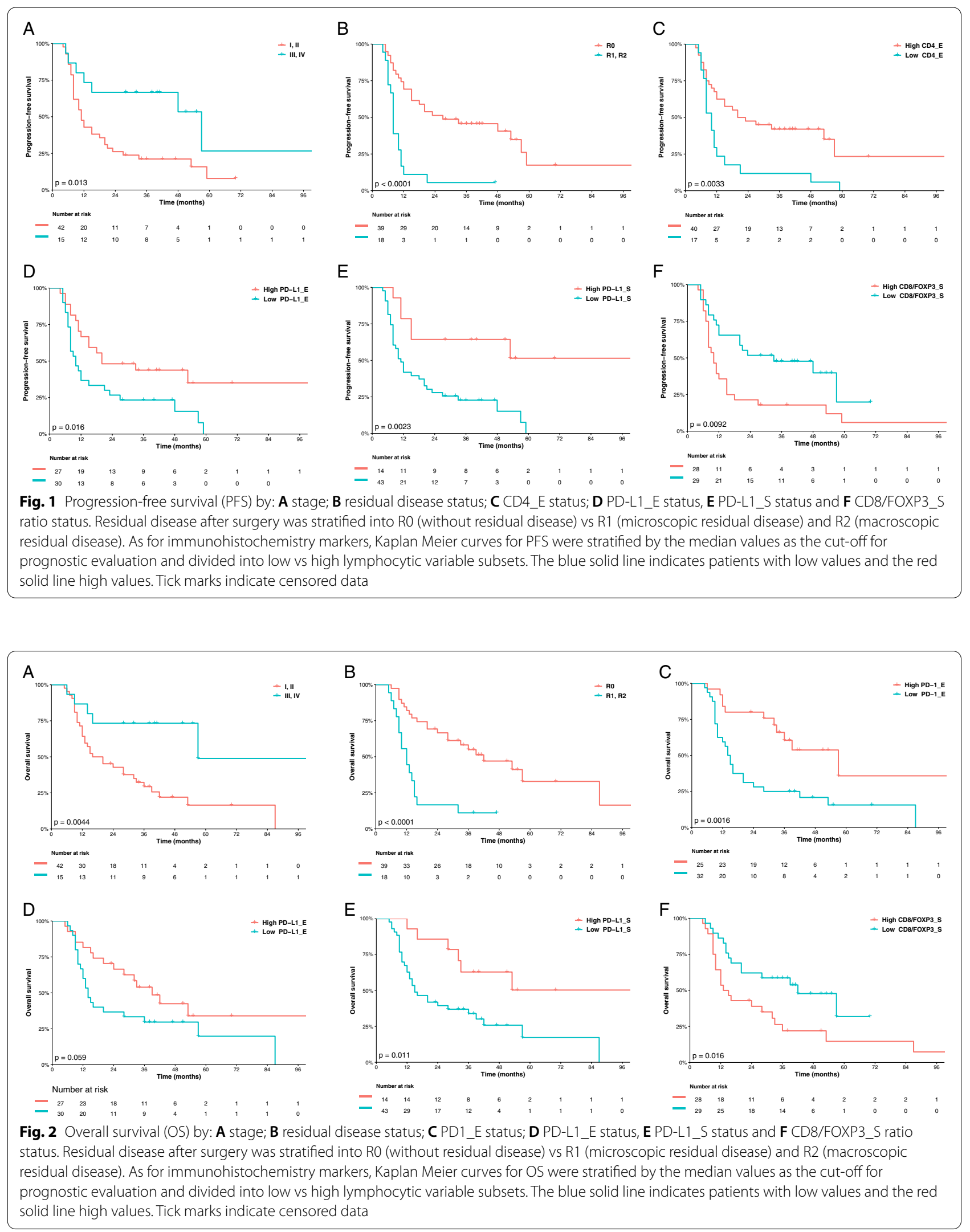
Conversely, our current results suggested that high CD8/FOXP3_S and CD4/FOXP3_S ratios significantly yielded poorer survival outcomes.

Such conflicting findings might be strongly explained by tumor heterogeneity based on the histologic distribution of TILs at the tumor site. The aforementioned studies might have used TMAs that were built up with cores of diverse numbers, sizes and from distinct areas in the surgical samples (peri-tumoral or intra-tumor), consequently with different proportions of other immune cell subtypes that might have important roles in the TME (Myeloid-derived suppressor cells, MDSCs, Macrophages M2, granulocytes, B cells and so on). That said, these other subpopulations of TILs could influence the prognostic impact of the CD8+/FOXP3+ and CD4+/FOXP3+ ratios [33]. Salet and Elkordab [34] have suggested that Treg (FOXP3+) should be performed in subgroups based on their location in the tumor tissue and the current prognostic influence of each subgroup should be evaluated individually.

This cohort also suggested that highly expressed PD-L1, both in the epithelial and sarcomatous components, was found to be significant and independent marker for favorable PFS and OS. Likewise, highly expressed PD-1_E also showed a favorable association with OS in our cohort. PD-1/PD-L1 axis immune checkpoint signaling, known to play an important role in cancer progression and survival, is currently one of the most explored pathways in gynecological cancers [35]. Along with mismatch repair deficiency (dMMR), microsatellite instability (MSI) status and tumor mutational burden (TMB), PD-L1 has been identified as a potential predictive biomarker for endometrial cancer in some phase II clinical trials with immune checkpoint inhibitors [36, 37]. The cohort of 700 patients with uterine cancer performed by Engerud et al. [38] showed PD-L1 and PD-1 expression in 59 and $63 \%$ in primary tumors, respectively, with similar expression patterns across microsatellite stable (MSS) and MSI tumors. However, they did not influence survival outcomes.

Some other findings of this cohort suggest that the lymphocyte markers evaluated (CD3, CD4, CD8 and FOXP3), as well as PD-L1, PD-L2 and PD-1, seemed to be more highly expressed amidst the sarcomatous component. Therefore, UCS with sarcomatous dominance (defined as the proportion of the sarcoma component being greater than $50 \%$ in the primary tumor within all examined hysterectomy specimens), which was associated with shorter survival in previous reports $[20,21]$, may be targetable by immunotherapeutic agents. Unfortunately, the analysis of sarcomatous dominance is beyond the scope of the current study. Some data point to the fact that the more advanced the stage of solid tumors, the greater the expression of TILs markers in the TME favoring tumor progression [39].

The survival analyzes further exhibited that advanced stage (III/IV) and incomplete debulking are significantly associated with poorer PFS and OS outcomes. The negative prognostic impact of these clinicopathological variables has already been shown in other cohorts of carcinosarcoma [19, 20, 40, 41]. In a secondary analysis of a prior multicenter retrospective study, Matsuo et al. [42] suggested that LVI containing a sarcomatous component might be a predictor of decreased survival for women with UCS. However, LVI showed no significant association with survival in our cohort.

The strengths of this study lie in the novelty of the indepth analysis of TME data in UCS by presenting the characteristics of the lymphomononuclear infiltrate correlating with clinicopathological features and evaluating the impact on survival. The study population is homogenous in that we only included patients with carcinosarcoma who underwent primary surgery and subsequently adjuvant chemotherapy with CP. Moreover, all surgical samples were double-checked by experienced pathologists. Lastly, a thorough descriptive presentation of clinicopathological variables was performed and multivariate analyzes reinforce the internal validity of the results.

The weaknesses of this study are strongly related to the fact that it is a retrospective analysis. So, some missing confounding factors may exist in the analysis. For example, even with well-established institutional protocols, the choice of adjuvant treatment with chemotherapy and or radiotherapy was at the discretion of the care providers. Additionally, the small sample may have been insufficient to ensure adequate power to detect differences in survival for some TME markers. Furthermore, molecular analysis was not performed in this study.

\section{Conclusion}

This is possibly the first report to delve into the composition of TME in carcinosarcoma. Assessments of immune markers for progression and survival outcomes may have been impaired by the small sample. However, due to the increased prevalence of high expression of immune markers in this setting, the findings can respectfully provide some basis for formulating studies to evaluate novel therapeutic strategies with immunotherapeutic agents. 


\section{Supplementary Information}

The online version contains supplementary material available at https://doi. org/10.1186/s12885-021-09026-6.

Additional file 1 : Table 1. Baseline clinicopathological characteristics of eligible patients $(N=57)$. Table 2 . Treatment data of the study population $(N=57)$. Table 3. Paired scores of immunohistochemistry markers for epithelial and sarcomatous components analyzed by the Wilcoxon signed-rank test. Table 4. Crude and adjusted Hazards Ratios for Carcinosarcoma progression-free survival (PFS) estimated by univariate analysis and multivariate analysis. Table 5. Crude and adjusted Hazards Ratios for Carcinosarcoma overall survival (OS) estimated by univariate analysis and multivariate analysis. Figure 1. Boxplots representing the distributions of the values of markers. Figure $\mathbf{2}$. Representative pictures of lymphocyte infiltration in uterine carcinosarcoma showing immunohistochemical staining of high $\mathrm{CD} 3+, \mathrm{CD} 4+, \mathrm{CD} 8+, \mathrm{FOXP} 3+, \mathrm{PD}-1+, \mathrm{PD}-\mathrm{L} 1+$ and PD-L2 +. Original magnification: $\times 400$ ( $\times 40$ objective).

\section{Acknowledgements}

The authors are indebted to all patients and their families for their trust and participation and for the provision of biological material for research purposes. The authors wish to thank Mrs. Isabele Small for technical support with statistical analysis.

\section{Authors' contributions}

JLS and ACM designed and planned the study. JLS, LZA, FRR and GGM collected and analyzed clinical data. JLS, CBPC and MHB wrote the main manuscript and MHB, ACM and CBPC edited the manuscript. JLS and ACM performed statistical analysis and reviewed the statistical analysis. All authors read and approved the final manuscript.

\section{Funding}

The authors declare that this study has received no financial support.

\section{Availability of data and materials}

The datasets generated during and/or analyzed during the current study are available from the corresponding author on reasonable request.

\section{Declarations}

\section{Ethics approval and consent to participate}

The study was approved by the institutional review board (Comitê de Ética em Pesquisa do Instituto Nacional de (âncer, CEP-INCA) and conducted in accordance with good clinical practice guidelines. Considering the observational retrospective design of the study, the institutional review board decided in favor of waiving the informed consent from all patients

\section{Consent for publication}

Not applicable.

\section{Competing interests}

The authors declare that they have no conflicts of interest.

\section{Author details}

${ }^{1}$ Division of Clinical Research and Technological Development, Brazilian National Cancer Institute, Rio de Janeiro, Brazil. ${ }^{2}$ Gynecologic Oncology Section, Brazilian National Cancer Institute, Rio de Janeiro, Brazil. ${ }^{3}$ Division of Pathology, Brazilian National Cancer Institute, Rio de Janeiro, Brazil. ${ }^{4}$ Immunology and Tumor Biology Program, Brazilian National Cancer Institute, Rio de Janeiro, Brazil. ${ }^{5}$ Vice-Presidency of Research and Biological Collections (VPPCB), Oswaldo Cruz Foundation (FIOCRUZ), Rio de Janeiro, Brazil.

Received: 28 March 2021 Accepted: 17 November 2021 Published online: 07 December 2021

\section{References}

1. Cherniack A, Shen H, Walter V, Stewart C, Murray B, Bowlby R, et al. Integrated molecular characterization of uterine carcinosarcoma. Cancer Cell. 2017;31(3):411-23.

2. Cantrell LA, Blank SV, Duska LR. Uterine carcinosarcoma: a review of the literature. Gynecol Oncol. 2015;137(3):581-8.

3. Gorai I, Yanagibashi T, Taki A, Udagawa K, Miyagi E, Nakazawa T, et al. Uterine carcinosarcoma is derived from a single stem cell: an in vitro study. Int J Cancer. 1997:72(5):821-7.

4. Gotoh O, Sugiyama Y, Takazawa Y, Kato K, Tanaka N, Omatsu K, et al. Clinically relevant molecular subtypes and genomic alteration-independent differentiation in gynecologic carcinosarcoma. Nat Commun. 2019;10(1):4965.

5. El-Nashar SA, Mariani A. Uterine carcinosarcoma. Clin Obstet Gynecol. 2011;54(2):292-304.

6. Garg G, Shah JP, Kumar S, Bryant CS, Munkarah A, Morris RT. Ovarian and uterine carcinosarcomas: a comparative analysis of prognostic variables and survival outcomes. Int J Gynecol Cancer Off J Int Gynecol Cancer Soc. 2010;20(5):888-94.

7. Sherman ME, Devesa SS. Analysis of racial differences in incidence, survival, and mortality for malignant tumors of the uterine corpus. Cancer. 2003;98(1):176-86.

8. Schreiber RD, Old LJ, Smyth MJ. Cancer immunoediting: integrating immunity's roles in cancer suppression and promotion. Science. 2011;331(6024):1565-70.

9. Vinay DS, Ryan EP, Pawelec G, Talib WH, Stagg J, Elkord E, et al. Immune evasion in cancer: mechanistic basis and therapeutic strategies. Semin Cancer Biol. 2015;35:S185-98.

10. da Silva JL, Dos Santos ALS, Nunes NCC, de Moraes Lino da Silva F, CGM F, de Melo AC. Cancer immunotherapy: the art of targeting the tumor immune microenvironment. Cancer Chemother Pharmacol. 2019;84(2):227-40

11. Francisco LM, Salinas VH, Brown KE, Vanguri VK, Freeman GJ, Kuchroo VK, et al. PD-L1 regulates the development, maintenance, and function of induced regulatory T cells. J Exp Med. 2009;206(13):3015-29.

12. Patsoukis N, Duke-Cohan JS, Chaudhri A, Aksoylar H-I, Wang Q, Council A, et al. Interaction of SHP-2 SH2 domains with PD-1 ITSM induces PD-1 dimerization and SHP-2 activation. Commun Biol. 2020;3(1):1-13.

13. Spranger S, Spaapen RM, Zha Y, Williams J, Meng Y, Ha TT, et al. Up-regulation of PD-L1, IDO, and T(regs) in the melanoma tumor microenvironment is driven by CD8(+) T cells. Sci Transl Med. 2013:5(200):200ra116.

14. Powell MA, Filiaci VL, Rose PG, Mannel RS, Hanjani P, Degeest K, et al. Phase II evaluation of paclitaxel and carboplatin in the treatment of carcinosarcoma of the uterus: a gynecologic oncology group study. J Clin Oncol Off J Am Soc Clin Oncol. 2010;28(16):2727-31.

15. Creasman W. Revised FIGO staging for carcinoma of the endometrium. Int J Gynaecol Obstet Off Organ Int Fed Gynaecol Obstet. 2009;105(2):109.

16. Udall M, Rizzo M, Kenny J, Doherty J, Dahm S, Robbins P, et al. PD-L1 diagnostic tests: a systematic literature review of scoring algorithms and test-validation metrics. Diagn Pathol. 2018;13 [cited 2020 Aug 22]. Available from: https://www.ncbi.nlm.nih.gov/pmc/articles/PMC5807740/.

17. Zhang L, Conejo-Garcia JR, Katsaros D, Gimotty PA, Massobrio M, Regnani $\mathrm{G}$, et al. Intratumoral T cells, recurrence, and survival in epithelial ovarian cancer. N Engl J Med. 2003;348(3):203-13.

18. R Core Team. R: a language and environment for statistical computing. Vienna: R Foundation for Statistical Computing; 2014. Available from: http://www.R-project.org/

19. Matsuo K, Takazawa Y, Ross MS, Elishaev E, Podzielinski I, Yunokawa M, et al. Significance of histologic pattern of carcinoma and sarcoma components on survival outcomes of uterine carcinosarcoma. Ann Oncol Off J Eur Soc Med Oncol. 2016;27(7):1257-66.

20. Matsuo K, Takazawa Y, Ross MS, Elishaev E, Yunokawa M, Sheridan TB, et al Proposal for a risk-based categorization of uterine carcinosarcoma. Ann Surg Oncol. 2018;25(12):3676-84.

21. Matsuo, K., Takazawa, Y., Ross, M. S., Elishaev, E., Yunokawa, M., Sheridan, T. B., , et al. Characterizing sarcoma dominance pattern in uterine carcinosarcoma: homologous versus heterologous element. Surg Oncol 2018;27(3):433-440 
22. Matsuo K, Ross MS, Machida H, Blake EA, Roman LD. Trends of uterine carcinosarcoma in the United States. J Gynecol Oncol. 2018;29(2) [cited 2020 Sep 9]. Available from: https://www.ncbi.nlm.nih.gov/pmc/articles/ PMC5823983/.

23. Wallace AE, Gibson DA, Saunders PTK, Jabbour HN. Inflammatory events in endometrial adenocarcinoma. J Endocrinol. 2010;206(2):141-57.

24. Ohno S, Ohno Y, Suzuki N, Kamei T, Koike K, Inagawa H, et al. Correlation of histological localization of tumor-associated macrophages with clinicopathological features in endometrial cancer. Anticancer Res. 2004;24(5C):3335-42.

25. Wallace AE, Sales KJ, Catalano RD, Anderson RA, Williams ARW, Wilson MR, et al. Prostaglandin F2alpha-F-prostanoid receptor signaling promotes neutrophil chemotaxis via chemokine (C-X-C motif) ligand 1 in endometrial adenocarcinoma. Cancer Res. 2009;69(14):5726-33.

26. Giatromanolaki A, Bates GJ, Koukourakis MI, Sivridis E, Gatter KC, Harris AL, et al. The presence of tumor-infiltrating FOXP3+ lymphocytes correlates with intratumoral angiogenesis in endometrial cancer. Gynecol Oncol. 2008;110(2):216-21.

27. Levinson K, Dorigo O, Rubin K, Moore K. Immunotherapy in gynecologic cancers: what we know now and where we are headed. Am Soc Clin Oncol Educ Book. 2019; [cited 2020 Sep 9]; Available from: https://ascop ubs.org/doi/pdf/10.1200/EDBK_237967.

28. Zhang S, Minaguchi T, Xu C, Qi N, Itagaki H, Shikama A, et al. PD-L1 and CD4 are independent prognostic factors for overall survival in endometrial carcinomas. BMC Cancer. 2020;20(1):127.

29. de Jong RA, Leffers N, Boezen HM, ten Hoor KA, van der Zee AGJ, Hollema $\mathrm{H}$, et al. Presence of tumor-infiltrating lymphocytes is an independent prognostic factor in type I and II endometrial cancer. Gynecol Oncol. 2009;114(1):105-10.

30. Jamiyan T, Kuroda H, Yamaguchi R, Nakazato Y, Noda S, Onozaki M, et al. Prognostic impact of a tumor-infiltrating lymphocyte subtype in triple negative cancer of the breast. Breast Cancer. 2020;27(5):880-92.

31. Curiel TJ, Coukos G, Zou L, Alvarez X, Cheng P, Mottram P, et al. Specific recruitment of regulatory $T$ cells in ovarian carcinoma fosters immune privilege and predicts reduced survival. Nat Med. 2004;10(9):942-9.

32. Ore-Arce M, Ballester Cl, Lopez-Reig R, Parra-Grande M, Romero I, LopezGuerrero JA, et al. Clinicopathological significance and prognostic value of intratumoral and peritumoral lymphocytes in endometrial cancer patients. J Clin Oncol. 2019;37(15_suppl):e17116.

33. Sideras K, Galjart B, Vasaturo A, Pedroza-Gonzalez A, Biermann K, Mancham S, et al. Prognostic value of intra-tumoral CD8+/FoxP3+ lymphocyte ratio in patients with resected colorectal cancer liver metastasis. J Surg Oncol. 2018;118(1):68-76.

34. Saleh $\mathrm{R}$, Elkord E. FoxP3+T regulatory cells in cancer: prognostic biomarkers and therapeutic targets. Cancer Lett. 2020;490:174-85.

35. Heong V, Ngoi N, Tan DSP. Update on immune checkpoint inhibitors in gynecological cancers. J Gynecol Oncol. 2017;28(2) [cited 2020 Sep 12]. Available from: https://www.ncbi.nlm.nih.gov/pmc/articles/PMC53 23287/.

36. Le DT, Uram JN, Wang $H$, Bartlett BR, Kemberling $H$, Eyring AD, et al. PD-1 blockade in tumors with mismatch-repair deficiency. N Engl J Med. 2015;372(26):2509-20.

37. Chung HC, Ros W, Delord J-P, Perets R, Italiano A, Shapira-Frommer R, et al. Efficacy and safety of Pembrolizumab in previously treated advanced cervical cancer: results from the phase II KEYNOTE-158 study. J Clin Oncol Off J Am Soc Clin Oncol. 2019;37(17):1470-8.

38. Engerud H, Berg HF, Myrvold M, Halle MK, Bjorge L, Haldorsen IS, et al. High degree of heterogeneity of PD-L1 and PD-1 from primary to metastatic endometrial cancer. Gynecol Oncol. 2020;157(1):260-7.

39. Hendry S, Salgado R, Gevaert T, Russell PA, John T, Thapa B, et al. Assessing tumor infiltrating lymphocytes in solid tumors: a practical review for pathologists and proposal for a standardized method from the International Immuno-Oncology Biomarkers Working Group. Adv Anat Pathol. 2017;24(6):311-35.

40. Manzerova J, Sison CP, Gupta D, Holcomb K, Caputo TA, Parashar $B$, et al. Adjuvant radiation therapy in uterine carcinosarcoma: a population-based analysis of patient demographic and clinical characteristics, patterns of care and outcomes. Gynecol Oncol. 2016;141(2):225-30.
41. Matsuo K, Omatsu K, Ross MS, Johnson MS, Yunokawa M, Klobocista MM, et al. Impact of adjuvant therapy on recurrence patterns in stage I uterine carcinosarcoma. Gynecol Oncol. 2017;145(1):78-87.

42. Matsuo K, Takazawa Y, Ross MS, Elishaev E, Yunokawa M, Sheridan TB, et al. Significance of Lymphovascular space invasion by the Sarcomatous component in uterine Carcinosarcoma. Ann Surg Oncol. 2018;25(9):2756-66.

\section{Publisher's Note}

Springer Nature remains neutral with regard to jurisdictional claims in published maps and institutional affiliations.
Ready to submit your research? Choose BMC and benefit from:

- fast, convenient online submission

- thorough peer review by experienced researchers in your field

- rapid publication on acceptance

- support for research data, including large and complex data types

- gold Open Access which fosters wider collaboration and increased citations

- maximum visibility for your research: over $100 \mathrm{M}$ website views per year

At BMC, research is always in progress.

Learn more biomedcentral.com/submissions 